\title{
Are American Universities Mismanaged?: Tenure vs Non-Tenure Faculty Employment Decisions
}

\author{
G. Thomas Sav \\ Raj Soin College of Business, Wright State University, Ohio, USA \\ tom.sav@wright.edu
}

\begin{abstract}
This paper empirically tests the extent to which public universities in the United States are potentially mismanaged. The focus rests with university managerial employment decisions regarding the continuing substitution of less costly non-tenure track teaching faculty for tenured and tenure track faculty and the extent to which those decisions affect student graduation success. Panel data covering ten academic years, 2004-05 through 2013-14 are employed using ordinary least squares and stochastic frontier analysis specifications. The latter provides tests of the inefficiency effects of managerial employment decisions and academic year estimates of technical efficiency. In both cases, the results provide statistically strong evidence that tenured faculty lead to increased student graduation success while increases in non-tenured faculty have negative effects on student graduation rates. The stochastic results provide strong evidence of efficiency gains due to tenured faculty and increased inefficiency arising from non-tenure track faculty employment. While universities appear to have managed efficiency gains as a possible result of the Great Recession, those gains quickly evaporated in both 2012 and 2013. Separate estimates for research vs. lower level comprehensive universities, indicate that the former maintain greater operating efficiencies. Given that public universities are being subject to new funding models that tie funding to the production of student success rates, the continuing non-tenure track employment substitution suggests that universities are potentially mismanaged in generating funding support for faculty employment and student success.
\end{abstract}

Keywords: Tenure, non-tenure, faculty employment, stochastic frontier, university efficiency

\section{Introduction}

This paper investigates managerial decisions in American publicly funded universities as those decisions relate to the employment of tenured and tenure track faculty relative to non-tenure track faculty and the efficiency consequences of producing student graduation success. The empirical results are robust in indicating that tenured faculty employment increases student graduation success and university efficiencies. In contrast, increases in the employment composition of non-tenure track faculty have an inefficiency producing effect that decrease student success rates. The empirical results suggest that university managerial decisions may not, in part, be in sync with the reality of external forces guiding their future and, in particular, their ability to sustain or improve their financial funding position from public agencies. That, in turn, suggests that U.S. public universities are mismanaged. The potential mismanagement can be attributed to the continuing evolution of internal decision-making on the one hand and the changing external political demands and funding models being imposed upon universities on the other hand. Three combinations of internal and external factors are relevant. First, in terms of internal employment decision-making, university administrators have continued to reallocate internal resources toward the hiring of non-tenure track faculty in substitution for tenured and tenure track faculty. The American Association of University Professors reports (American Association of State Colleges and Universities, 2006) that over the past four decades full time tenured faculty positions have decreased by $26 \%$ and tenure track faculty lines have declined by $50 \%$. In the present paper, the data for U.S. public universities indicate that, on average, $44 \%$ of university faculty is on employed under non-tenure track employment contracts. University administrators and their controlling boards of trustees likely view the substitution of lower salaried non-tenure track teaching faculty for higher salaried tenured and tenure track teaching faculty as good cost-cutting business decisions.

Second, decreases in government funding of public universities has continued to decline and deteriorate university revenues derived from tax supported dollars. Moreover, the decrease in funding support accelerated with the arrival of the Great Recession (officially dated December 2007 to June 2009). In the 2004 academic year, state government funding generated $32 \%$ of university funding and thereafter declined to $23 \%$ in the 2013 academic year (GAO, 2014). With increasing student enrollments, budgetary cuts placed greater pressures on university administrators to substitute lower salaried non-tenure track teaching faculty for higher salaried tenured and tenure track teaching faculty. Third, the political machinery and funding 
agencies responsible for the funding cuts have imposed increasingly new demands on universities to do more with less by increasing the efficiency with which they produce publicly provided higher education. That same machinery has implemented new funding models that subject universities to greater accountability in tying public funding to university measures of producing student success outcomes. Thirty two of the fifty states in the U.S. have implemented funding formulas that tie public university funding to student success measures and five additional states are in transition to doing the same (National Conference of State Legislators, 2015). In particular, publicity regarding low student graduation successes among public universities have brought that political pressure to implement funding models that require universities to demonstrate improvements in student academic success leading to improved retention and, ultimately improved student graduation rates. Therein lies, in part, a managerial dilemma but in reality a potential problem with the mismanagement of U.S. publicly supported universities. That is, if university administrative decisions continue to rest with cost cutting substitutions of the employment of non-tenure track faculty for tenured and tenure track faculty and the former negatively affect student success rates while funding models are increasingly tied to the production of student success, then university administrative decision-making is apparently incongruent with successful managerial practices.

The empirical results alluded to the opening paragraph and in reference to the above realities are based on panel data for U.S. universities engaged in both undergraduate and graduate education over ten academic years, 2004-05 through 2013-14. The full panel consists of 3,465 observations. Two empirical model specifications are used to evaluate the university production of student success as measured by graduation rates. An ordinary least squares (OLS) model is used at the outset and is followed by a stochastic frontier analysis (SFA) model. The latter is employed to estimate the inefficiency effects of university managerial employment decisions and, in addition, generate efficiency estimates of university production of student graduation success rates. In both specifications, university administrative decisions are incorporated as related to contractual employment arrangements of tenured faculty, tenure track faculty, and non-tenure track faculty. In addition, university institutional control variables are included as measures of administrative allocations of internal resources to support student instruction and faculty research (as measures of university research intensity vs student support intensity), as well as, student enrollment measures as related to university student application acceptances and student enrollment stochastic aptitude abilities (as measures of university quality standards and student academic abilities). The paper proceeds with a brief literature review followed by the empirical methodology, an overview of the panel data, a detailed analysis of the empirical results, and a summary with concluding remarks.

\section{Literature Review}

To date, only a handful of studies have investigated the effects of teaching faculty on student success rates. A study by Bettinger and Long (2010) states that such is "virtually absent from the literature" but the study provides a literature review of six studies that can be considered to be of tangential relevance. Sav's study (2012a) indicates that no new studies have appeared and provides a summary of the Bettinger and Long (2010) literature review. As of this writing, an exhaustive literature search did not find any new studies since that provided by Sav (2012a). Thus, there is little need to repeat those previous literature reviews other than to provide a very brief summary. However, the review ends with a review of the most current literature that indicates a continuing concern with the decline in tenure relative to non-tenure track employment in academe. Three studies are only focused on the effects of graduate teaching assistants on student success. Norris (1991) and Fleisher, et al. (2002) find that teaching assistants do not affect student performance if, according to Fleisher, et al. (2002), non-native speaking assistants receive appropriate English speaking training. Another three studies examine the effects of full time faculty compared to adjunct and part-time faculty on student interest in subjects or on graduation rates. The Ehrenberg and Zhang (2005) study finds that part-time and non-tenure track faculty employment reduces graduation rates. Bettinger and Long (2004) find that young aged adjuncts have negative effects on student retention interest but only in specific disciplines. In the later Bettinger and Long (2010) study, employing a different methodology, they reach the same basic conclusions.

These studies use data either from a single university, e.g., Norris (1991) and Fleisher. Hashimoto and Weinberg (2002), or from universities in a single state in the U.S., e.g., Bettinger and Long (2004) and 
Bettinger and Long (2010), or from a sample of U.S. universities that report only student specific aptitude test scores. None of the studies investigate the effects of full-time teaching faculty across different employment contractual arrangements imposed by university management. In addition, none of studies investigate those effects across all U.S. universities. In contrast, the study by Sav (2012a) focuses on differential effects of tenured, tenure-track, and non-tenure track employment contractual arrangements on student graduation success. Moreover, the study casts a wide net of those effects using data for all U.S. universities. The findings support the notion that tenured faculty and tenure track faculty employment produce improvements in student graduation success while hiring faculty under non-tenure track contracts are detrimental to student success. Another study by Sav (2012b) evaluates the management of U.S. public colleges and produces operating efficiency estimates by uses data only for two-year colleges and could not account for faculty employment differentials at that lower level of U.S. public higher education.

More recently, additional research has focused on the continuing concern of the tenure process in higher education. However, it has taken a different path than the studies reviewed in the above account. Lawrence, Celis and Ott (2014) evaluate faculty experiences with the tenure process and the potential problems with procedural fairness in moving untenured faculty into tenured positions. Zhang, Ehrenberg, and Liu (2015) use panel data models to examine faculty employment changes among four year colleges and universities. They conclude, in support of the present study, that institutions have, in response to deteriorating financial situations, increasingly employed faculty whose salaries are relatively inexpensive, thereby increasing the share of non-tenure track faculty relative to tenure track faculty. Kezar and Gehrke (2016) surveyed academic deans with respect to their views and practices in employing non-tenure track faculty. Using OLS they find that the increased employment of non-tenure track faculty are not in the best interests of academic deans but is the result of external pressures imposed upon their decision-making. Cater, Lew and Pivato (2016) propose that faculty research accomplishments attract tuition-paying students and, therefore, increase university revenues. Thus, they find that a profit-maximizing university will place higher value on more current research productive junior faculty than to the past accumulated research productivity of tenured faculty. They test the proposition that tenure-based contracts are therefore non-optimal. Testing the efficiency of tenure contracts, they conclude, in counter-argument, that declining research productivity of tenured faculty are not the result of any disincentive of the tenure process in academe. While that study focuses on research productivity it lends support to the current inquiry of the effects of faculty tenure on student graduation rates.

To investigate those tenure effects on student success, the present study parallels that of Sav (2012a) but offers advantages. First and foremost, that earlier study was based on university data constrained to only four academic years, 2005 to 2009. That could not account for the potential effects of the Great Recession (December 2007 to June 2009) on university operating budget cuts or the increasing student enrollments driven by the increases in recessionary unemployment or the U.S. government offered grants to student higher education enrollment for retraining the unemployed. In addition, that study did not account for some of the specific university imposed constraints pertaining to student acceptance rates, student enrollment rates upon acceptance, and incoming student scholastic aptitude preparations or academic abilities for higher education success.

\section{Methodology}

The methodology is based on universities producing student success toward graduation. That production is empirically estimated using ordinary least squares (OLS) and stochastic frontier analysis (SFA). In both cases, the primary focus rests with the university's administrative decisions and allocation of resources in employing teaching faculty under different legally contractual arrangements while also considering the allocation of resources to student support, faculty research support, and imposing quality constraints on student enrollments. The OLS estimation is intended to estimate the direct effects of all managerial decisions on student success. The SFA estimation is employed to estimate the efficiency or inefficiency of university managerial decisions in employing different compositions of faculty in producing student graduation success. In addition, the SFA model provides university production efficiency estimates for comparison across universities. For both the OLS and SFA methodology, panel data pertaining to university production over time 
is employed. The OLS estimates of producing student success (Student Success) for university $i=1, \ldots, \mathrm{N}$ over $t$ academic years, $t=1, \ldots, \mathrm{T}$, is specified as follows:

$$
\text { StudentSucesss }_{i t}=\alpha_{0}+\sum \alpha_{i t} X_{i t}+\sum \text { Faculty }_{i t}+\varepsilon_{i t}
$$

Here, the $X$ variables are intended to capture the institutional allocation of resources to alternative internal missions and to establish specific quality student enrollment requirements. The Faculty variables represent measures of the composition of faculty under different legal contracts arranged by university administrators in the allocation of resources toward the employment of teaching faculty. Epsilon is the usual OLS error term. In order to measure the efficiency with which universities produce student success, the SFA specification is employed. Invoking the Cobb-Douglas production function, the SFA specification, following Battese and Coelli (1995) and Coelli et al. (1999), is as follows (whereby the natural logarithm is denoted by $l n$ ):

$\ln$ StudentSucesss $_{i t}=\beta_{0}+\sum \beta_{i t} \ln X_{i t}+\varepsilon_{i t}$

Andepsilon is a composed error term such that

$\varepsilon_{i t}=V_{i t}-U_{i t}$

The $V$ represents the usual random shocks to university's ability to produce student graduation successes while $U$ is intended to capture the managerial inefficiency related to the production of that graduation success. That is,

$U_{i t}=\alpha_{0}+\sum \xi_{i t} \ln$ Faculty $_{i t}+R_{i t}$

where Faculty now enter as inefficiency (efficiency) effects in determining the inefficiency (efficiency) of managerial decisions in allocating resources to the employment of teaching faculty under alternative contractual arrangements. $\mathrm{R}$ is a random error term that follows the distribution per the work of Battese and Coelli (1995) and Coelli et al. (1999).

With that SFA inefficiency embedded, the university's overall efficiency in producing student success is determined by the following:

UniversityEfficiency $_{i t}=\exp \left(-U_{i t}\right)=\exp \left(-\right.$ Faculty $\left._{i t} \phi-R_{i t}\right)$

In this case, the estimated coefficients on the Faculty employment and the resulting university effect on inefficiency will produce negative coefficients that represent inefficiency reductions (i.e., efficiency gains or improvements) and positive coefficients will measure inefficiency increases (i.e., efficiency deterioration).

Panel Data: The U.S. Department of Education, National Center for Education Statistics, provides annual academic year data pertaining to U.S. higher education institutions. The data cover a wide range of college and university revenue, expenditure, student enrollment, student graduation success, measures of potential student success, and faculty employment status. The data are publicly available via the Integrated Postsecondary Education Data System (IPEDS). Given the time lag in the reporting and processing of final release data, the current study draws data from the ten academic years of IPEDS, 2004-2013 (i.e., academic years 2004-05 through 2013-2014). However, there is some variability in reporting institutional data that generates missing observations across colleges and universities. In the present study it was possible to include a total of 3,465 institutions over the ten academic years. The panel is unbalanced in that it varies from 333 to 360 institutions in any given academic year. Moreover, the panel includes colleges and universities that offer both undergraduate and graduate degree programs. Using the Carnegie classification of higher education institutions embedded in IPEDS, research level and comprehensive level universities are included in the panel. Thus, two-year associate degree and other lower level postsecondary higher education institutions in the U.S. are not included in the panel data. Table1 presents a summary description of the available measures and variables that capture the potential relationship between student success in universities and the institutional structure, student higher education preparedness, and managerial employment decisions regarding faculty employment. 
Table 1: Description of Variables

\begin{tabular}{|c|c|}
\hline $\begin{array}{l}\text { Variables } \\
\text { Dependent }\end{array}$ & ariable \\
\hline GRADRATE & Students Completing Degrees in $150 \%$ of Normal Time to Graduate (\%) \\
\hline Independen & Variables \\
\hline TUITION & Tuition Charge: University Tuition Revenue per Student (\$) \\
\hline PELLGRT & Lower Income Federal Pell Grants per Undergraduate Student (\$) \\
\hline FEDGRT & Federal Government Grants per Student (\$) \\
\hline INSTRUCT & Institutional Instructional Expenditures per Student (\$) \\
\hline STUFAC & Institutional Student to Faculty Ratio (\#) \\
\hline RESLEVEL & Institutional Research Expenditures per Total Expenditures (\%) \\
\hline ACCEPT & Student Acceptance Rate: Accepted per Total Applicants (\%) \\
\hline ENROLL & Students that Enrolled per Students Accepted (\%) \\
\hline MATHSAT & $75^{\text {th }}$ percentile SAT Math Score of Students Enrolled (\#)* \\
\hline VERBSAT & $75^{\text {th }}$ percentile SAT Verbal Score of Students Enrolled $(\#)^{*}$ \\
\hline OLS Indeper & dent Variables and SFA Inefficiency Effect Variables \\
\hline TENURE & Percentage of Total Faculty Employed that are Tenured (\%) \\
\hline TRACK & Percentage of Total Faculty Employed that are on Tenure Track (\%) \\
\hline NOTRACK & Percentage of Total Faculty Employed that are Not on Tenure Track (\%) \\
\hline
\end{tabular}

The student graduation rate within $150 \%$ (i.e., within 5 years) of normal time to complete a four year degree program (GRADRATE) is used as a measure of student success within a university. That graduation rate is dependent on the institutional price, i.e., tuition (TUITION),students must pay to enroll and continue seeking a successful degree. However, included are potential differential tuition support effects funded by the federal government via low income student support by way of the Pell Grant Program (PELLGRT) and the broader federal grant program (FEDGRT). Three measures are included as related to university support of student success and the intensity of support to faculty research. The former includes INSTRUCT and STUFAC while the latter measure is RESLEVEL. As a combination of institutional quality and student quality there are four measures, including university student acceptance rates (ACCEPT), student enrollment rates per acceptance (ENROLL), enrolled student mathematical aptitudes (MATHSAT), and enrolled student verbal aptitudes (VERBSAT).

Table 2: Descriptive Statistics: Academic Years 2004-2013

\begin{tabular}{llllll}
\hline Variable & Mean & Std. Dev. & Median & Min & Max \\
\hline GRADRATE (\%) & 50.4 & 15.5 & 48.7 & 11.2 & 93.9 \\
TUITION (\$) & 4,560 & 2,370 & 3,959 & 237 & 20,466 \\
PELLGRT (\$) & 1,004 & 551 & 863 & 133 & 4,048 \\
FEDGRT (\$) & 120 & 174 & 72 & 0 & 2,356 \\
INSTRUCT (\$) & 4,756 & 2,436 & 4,054 & 1,274 & 28,492 \\
STUFAC (\#) & 20.7 & 6.4 & 19.7 & 6.5 & 58.6 \\
RESLEVEL (\%) & 4.7 & 5.4 & 2.1 & 0.0 & 32.0 \\
ACCEPT (\%) & 68.3 & 17.0 & 70.2 & 15.3 & 100.0 \\
ENROLL (\%) & 42.8 & 14.3 & 41.1 & 13.0 & 100.0 \\
MATHSAT (\#) & 578 & 61 & 580 & 260 & 800 \\
VERBSAT (\#) & 573 & 57 & 570 & 330 & 800 \\
TENURE (\%) & 39.5 & 11.3 & 38.5 & 9.3 & 78.9 \\
TRACK (\%) & 17.0 & 6.8 & 15.9 & 1.0 & 58.6 \\
NOTRACK (\%) & 43.5 & 14.6 & 44.4 & 1.5 & 83.2 \\
Observations & 3,465 & & & & \\
\hline
\end{tabular}

University managerial decisions related to the changing employment composition of teaching faculty are captured in three legally contractual employment arrangements, including faculty that are employed in tenured positions (TENURE) ,faculty employed in tenure track positions (TRACK), and faculty employed in 
non-tenure track positions (NOTRACK). Descriptive statistics for the full panel of observations are provided in Table 2. While on average $50 \%$ of students graduate (GRADRATE) within the five year window set by the available measure of student success, as is obvious by the standard deviation, minimum, and maximum graduation rates there is wide variability among universities. The variability in graduation rate success can, in part, be due to differential institutional and student characteristics captured in the ten covariates ranging from TUITION to VERBSAT. Moreover, student graduation success can be affected by variability in university managerial and administrative decisions related to the staffing of teaching faculty and the substitution of nontenure track faculty (NOTRACK) for tenure (TENURE) and tenure track (TRACK) faculty. The variability in that decision making is equally apparent in Table 2.

\section{Empirical Results}

Table 3: Results: Graduation Rate Dependent Variable, Pooled All Universities

\begin{tabular}{|c|c|c|c|c|c|c|}
\hline \multirow[b]{2}{*}{ Variable } & \multicolumn{3}{|c|}{ Ordinary Least Squares (OLS) } & \multicolumn{3}{|c|}{ Stochastic Frontier Analysis (SFA) } \\
\hline & Coeff & Std. Err. & t Value & Coeff & Std. Err. & t Value \\
\hline Constant & - & - & - & -2.3265 & 0.2474 & $*_{-}-9.40$ \\
\hline TUITION & 0.0013 & 0.0001 & $* 14.71$ & 0.1018 & 0.0087 & *11.73 \\
\hline PELLGRT & -0.0044 & 0.0003 & $*-14.9$ & -0.1181 & 0.0059 & $*_{-}-20.09$ \\
\hline FEDGRT & 0.0012 & 0.0009 & 1.39 & 0.0053 & 0.0030 & $* * 1.77$ \\
\hline INSTRUCT & 0.0003 & 0.0001 & $* 3.25$ & 0.1076 & 0.0119 & $* 9.02$ \\
\hline STUFAC & -0.4659 & 0.0282 & $*-16.55$ & -0.0938 & 0.0120 & $*-7.78$ \\
\hline RESLEVEL & -0.1319 & 0.0304 & $*_{-} 4.34$ & -0.0103 & 0.0016 & $*-6.30$ \\
\hline ACCEPT & -0.0993 & 0.0087 & $*-11.4$ & -0.0751 & 0.0098 & $*-7.65$ \\
\hline ENROLL & -0.1881 & 0.0105 & $*-17.85$ & -0.1457 & 0.0093 & $*-15.65$ \\
\hline MATHSAT & 0.0858 & 0.0058 & $* 14.75$ & 0.6867 & 0.0619 & $* 11.08$ \\
\hline VERBSAT & 0.0373 & 0.0059 & $* 6.26$ & 0.3445 & 0.0658 & *5.23 \\
\hline TENURE & 0.1254 & 0.0287 & $* 4.37$ & -0.9137 & 0.2172 & $*_{-4.21}$ \\
\hline TRACK & 0.0970 & 0.0286 & $* 3.39$ & 0.0501 & 0.0317 & $* * * 1.58$ \\
\hline NOTRACK & -0.1167 & 0.0238 & $*_{-} 4.91$ & 0.5593 & 0.1126 & $* 4.97$ \\
\hline Adjust $\mathrm{R}^{* *} 2$ & & & 0.977 & & & \\
\hline Prob $>F$ & & & $* 0.000$ & & & \\
\hline Sigma Sq & & & & 0.2528 & 0.0615 & $* 4.11$ \\
\hline Gamma & & & & 0.9699 & 0.0070 & *138.11 \\
\hline Log LL & & & & & & $* 1,230$ \\
\hline Log Ratio & & & & & & $* 828$ \\
\hline Observations & & & 3,465 & & & 3,465 \\
\hline
\end{tabular}

Note: Significant at $1 \%\left({ }^{*}\right), 10 \%\left({ }^{* *}\right)$, and $15 \%\left({ }^{* * *}\right)-(\mathrm{t}$ or other appropriate test).

The ordinary least squares (OLS) and stochastic frontier analysis (SFA) maximum likelihood estimates are presented in Table 3 when all universities are pooled (research and comprehensive). In order to account for possible underlying structural differences in research level compared to comprehensive level universities, Table 4 presents the separate level OLS and SFA estimates. In both Tables 3 and 4, the OLS estimates include the SFA employment inefficiency measures. It was not believed to be necessary to present OLS estimates that excluded the inefficiency measures since the test on Gamma in the SFA results determine whether or not those OLS estimates can be rejected in favor of the SFA estimates. Also, as noted, the OLS constant term is excluded so that it is possible to include all three faculty employment effects as covariates and, therefore, make relevant comparable evaluations to the inclusion of faculty employment as inefficiency terms in the SFA estimates. Turning first to the pooled results provided in Table 3, for the OLS results, 12 of the 13 independent variables are statistically significant at the $1 \%$ level of significance - only federal government grants (FEDGRT) fail to reach a reasonable level of significance. In addition, the adjusted R squared is better than 0.97. For the SFA results, 9 of the 10 independent variables reach the $1 \%$ level of significance and, in contrast to the OLS results, FEDGRT enters as significant at the $10 \%$ level. The SFA results, per the statistical significance of Gamma, also reveal that the faculty employment inefficiency terms should be included relative to an OLS speciation that excludes them. Likewise, the SFA likelihood ratio shows that the faculty employment inefficiency effects should be absent (jointly) from the model is rejected at the $1 \%$ level of 
statistical significance. In both the OLS and SFA estimates, the positive effect of TUITION on graduation success is consistent with the higher tuition universities being of the more premier and more selective universities in the U.S. The negative effect of PELLGRT is also expected if lower income government funded student enrollments are associated with less academically prepared students perhaps coming from underfunded primary and secondary school districts. Yet, as indicated, institutional expenditures on instruction (INSTRUCT) per student has a positive effect in assisting all students to successfully graduate. However, increases in the student to faculty ratio (STUFAC) works in the opposite direction with a strong negative effect on student success. That negative effect on student success is also present with regard to the increased research intensity of the institution (RESLEVEL).

The negative effect of higher acceptance rates of student applicants (ACCEPT) and the higher enrollment rates of accepted student applicants (ENROLL) indicates that lower quality universities struggle with improved graduation rates. As expected, the better academically prepared are the enrolled students as measured by both the mathematical (MATHSAT) and verbal (VERBSAT) preparedness, the greater is the university ability to successfully lead them to graduation success. As for the main focus of the paper, both the OLS and SFA results strongly support the notion that the administrative decision making in allocating employment resources to the hiring of teaching faculty under different contractual arrangements matters in the production of student academic graduation success. Under the OLS estimates, both tenured faculty (TENURE) and tenure track faculty (TRACK) significantly (at the 1\% level) and positively contribute to the graduation success of university students. And managerial decisions in substituting non-tenure track faculty (NOTRACK) for tenured employment or tenure track faculty lines is statistically significant (at the $1 \%$ level) as a detriment to student graduation success. In estimating the efficiency/inefficiency in those same administrative employment allocations, the SFA estimates are interpreted differently but are also robust. Negative coefficients in the faculty employment inefficiency terms represent efficiency improvements while positive coefficients represent inefficiency increases.

Thus, in the SFA estimates, tenured faculty employment (TENURE) enters as increasing the efficiency with which universities produce successful student graduation success. Although TENURE is significant at the 1\% level, the weaker effect of TRACK at the $15 \%$ level is not to be ignored being that that faculty on tenure track must be more focused on research output in order to successfully gain their bid and promotion to tenure. As a result, that may interfere with their teaching responsibilities and can be attributed to the increased inefficiency but only at the $15 \%$ level of statistical significance. On the other hand, the positive and significant (1\% level) effect of non-tenure track faculty in the SFA result indicates that university administrators that shift faculty hiring resources away from tenure line faculty to non-tenure track faculty employment are decreasing the efficiency with which they can successfully graduate their students. Turning to the research university vs comprehensive university separate level estimates provided in Table 4, both the OLS and SFA results meet the overall statistical significance requirements based on the adjusted R squared, $\mathrm{F}$ test, Gamma test, and the likelihood ratio test. However, the results indicate the presence of some basic structural differences in research compared to comprehensive universities in both the OLS and SFA results compared to the pooled university results provided in Table 3 .

For the OLS estimates, federal government grants (FEDGRT) plays a positive and statistically significant role in improving student graduation success among research universities but is negative although statistically insignificant among comprehensive universities. In contrast, institutional expenditures on instruction per student (INSTRUCT) is negative but statistically insignificant in improving that graduation success among research universities but positive and statistically significant for student success among comprehensive universities. With regard to faculty employment effects, tenure (TENURE) and tenure track faculty (TRACK) move students successfully toward successful graduation (although the latter reaches significance at only the $15 \%$ level). Non-tenure track faculty (NOTRACK) has a significant detrimental graduation effect. In comparison, while TENURE and TRACK have positive effects on student success among comprehensive universities, neither enters as being statistically significant. Still, the negative effect and statistically significant effect on NOTRACT faculty holds even among comprehensive universities. 
Table 4: Results: Research vs Comprehensive Universities

\begin{tabular}{|c|c|c|c|c|c|c|}
\hline \multirow{2}{*}{ Variable } & \multicolumn{3}{|c|}{ Ordinary Least Squares (OLS) } & \multicolumn{3}{|c|}{ Stochastic Frontier Analysis (SFA) } \\
\hline & Coeff & Std. Err. & t Value & Coeff & Std. Err. & t Value \\
\hline \multicolumn{7}{|l|}{ Research } \\
\hline Constant & - & - & - & -3.2608 & 0.3755 & $*-8.68$ \\
\hline TUITION & 0.0008 & 0.0001 & $* 7.69$ & 0.0656 & 0.0106 & $* 6.22$ \\
\hline PELLGRT & -0.0034 & 0.0005 & $*_{-7.11}$ & -0.0675 & 0.0076 & $*-8.88$ \\
\hline FEDGRT & 0.0044 & 0.0012 & $* 3.68$ & 0.0079 & 0.0039 & $* 2.05$ \\
\hline INSTRUCT & -0.0001 & 0.0001 & -0.64 & 0.0545 & 0.0140 & $* 3.90$ \\
\hline STUFAC & -0.5843 & 0.0420 & $*-13.93$ & -0.1443 & 0.0161 & $*_{-} 8.96$ \\
\hline RESLEVEL & -0.1425 & 0.0424 & $*-3.36$ & -0.0078 & 0.0042 & $* *-1.85$ \\
\hline ACCEPT & -0.1277 & 0.0135 & *-9.49 & -0.0961 & 0.0137 & $*-7.04$ \\
\hline ENROLL & -0.2303 & 0.0179 & $*-12.89$ & -0.1541 & 0.0122 & $*-12.61$ \\
\hline MATHSAT & 0.1100 & 0.0086 & $* 12.78$ & 0.9841 & 0.0909 & *10.83 \\
\hline VERBSAT & 0.0373 & 0.0081 & $* 4.61$ & 0.2979 & 0.0868 & $* 3.43$ \\
\hline TENURE & 0.0847 & 0.0489 & $* * 1.73$ & -0.7213 & 0.1217 & $*-5.93$ \\
\hline TRACK & 0.0811 & 0.0516 & $* * * 1.57$ & -0.0157 & 0.0355 & -0.44 \\
\hline NOTRACK & -0.1851 & 0.0417 & $*_{-4.44}$ & 0.5608 & 0.0731 & *7.67 \\
\hline Adjust R Sq & & & 0.986 & & & \\
\hline Prob $>F$ & & & $* 0.000$ & & & \\
\hline Sigma Sq & & & & 0.1290 & 0.0220 & *5.87 \\
\hline Gamma & & & & 0.9617 & 0.0066 & *146.44 \\
\hline Log LL & & & & & & *835 \\
\hline Log Ratio & & & & & & *503 \\
\hline Observations & & & 1,466 & & & 1,466 \\
\hline \multicolumn{7}{|c|}{ Comprehensive } \\
\hline Constant & - & - & - & -3.1357 & 0.4164 & $*-7.53$ \\
\hline TUITION & 0.0020 & 0.0002 & $* 12.05$ & 0.1319 & 0.0123 & *10.69 \\
\hline PELLGRT & -0.0051 & 0.0004 & *-13.37 & -0.1617 & 0.0086 & $*-18.84$ \\
\hline FEDGRT & -0.0002 & 0.0012 & -0.15 & 0.0066 & 0.0048 & 1.37 \\
\hline INSTRUCT & 0.0021 & 0.0003 & *6.48 & 0.2465 & 0.0244 & *10.10 \\
\hline STUFAC & -0.2337 & 0.0467 & $*-5.00$ & 0.0077 & 0.0198 & 0.39 \\
\hline RESLEVEL & -0.6378 & 0.1057 & $*_{-6.03}$ & -0.0082 & 0.0026 & $*-3.14$ \\
\hline ACCEPT & -0.0674 & 0.0119 & $*-5.64$ & -0.0513 & 0.0139 & $*-3.69$ \\
\hline ENROLL & -0.1542 & 0.0137 & $*-11.27$ & -0.1344 & 0.0136 & $*-9.85$ \\
\hline MATHSAT & 0.0634 & 0.0079 & $* 8.05$ & 0.5177 & 0.0838 & $* 6.18$ \\
\hline VERBSAT & 0.0424 & 0.0084 & *5.04 & 0.3975 & 0.0937 & $* 4.24$ \\
\hline TENURE & 0.0007 & 0.0434 & 0.02 & -0.5482 & 0.2892 & $*-1.99$ \\
\hline TRACK & 0.0408 & 0.0404 & 1.01 & -0.1459 & 0.1504 & -0.97 \\
\hline NOTRACK & -0.1364 & 0.0331 & $*-4.12$ & 0.2328 & 0.1009 & *2.31 \\
\hline Adjust $\mathrm{R}^{* *} 2$ & & & 0.970 & & & \\
\hline Prob $>F$ & & & $* 0.000$ & & & \\
\hline Sigma Sq & & & & 0.3628 & 0.1745 & *2.08 \\
\hline Gamma & & & & 0.9733 & 0.0115 & *84.57 \\
\hline Log LL & & & & & & $* 520$ \\
\hline Log Ratio & & & & & & $* 321$ \\
\hline Observations & & & 1,999 & & & 1,999 \\
\hline
\end{tabular}

Note: Significant at $1 \%\left({ }^{*}\right), 10 \%\left({ }^{* *}\right)$, and $15 \%\left({ }^{* * *}\right)-(\mathrm{t}$ or other appropriate test).

The research vs comprehensive structural differences are weak at best in the SFA results. That is, for comprehensive universities FEDGRT continues to be an insignificant role in graduation success. But relative to research universities the institutional student to faculty ratio (STUFAC) appears to have a positive but statistically insignificant effect among comprehensive universities while retaining its powerful positive effect among research universities. On faculty employment SFA inefficiency effects, the results are congruent across both university levels with respect to coefficient signs and statistical significance. That is, for research and 
comprehensive universities, increasing TENURE faculty leads to efficiency increases in producing student graduation success and increasing NOTRACK faculty increases the inefficiency in doing so. For both levels of universities, increasing the employment of tenure track faculty (TRACK) is an efficiency improving managerial decision and beneficial to student. The efficiency increasing effect, however, might suggest that the larger efficiency gains of TRACK are lagged and appear with their successful tenure (TENURE). Yet, the weaker effect of TENURE can also be attributed to the university administrative decisions to reduce tenure track faculty lines and substitute non-tenured faculty for those lines as is obvious in the descriptive statistics provided in Table 2 .

Table 5: University Efficiencies by Academic Year

\begin{tabular}{|c|c|c|c|c|c|}
\hline & Mean & Std. Dev. & Median & Min & $\operatorname{Max}$ \\
\hline \multicolumn{6}{|c|}{ Pooled Universities } \\
\hline 2004 & 0.848 & 0.122 & 0.896 & 0.339 & 0.987 \\
\hline 2005 & 0.846 & 0.115 & 0.891 & 0.422 & 0.980 \\
\hline 2006 & 0.839 & 0.116 & 0.881 & 0.444 & 0.979 \\
\hline 2007 & 0.835 & 0.114 & 0.872 & 0.422 & 0.974 \\
\hline 2008 & 0.828 & 0.123 & 0.869 & 0.325 & 0.974 \\
\hline 2009 & 0.832 & 0.122 & 0.875 & 0.302 & 0.976 \\
\hline 2010 & 0.855 & 0.116 & 0.898 & 0.332 & 0.975 \\
\hline 2011 & 0.859 & 0.112 & 0.902 & 0.294 & 0.974 \\
\hline 2012 & 0.851 & 0.116 & 0.893 & 0.288 & 0.972 \\
\hline 2013 & 0.847 & 0.115 & 0.884 & 0.331 & 0.974 \\
\hline $10 \mathrm{yr}$ & 0.844 & 0.117 & 0.888 & 0.288 & 0.987 \\
\hline \multicolumn{6}{|c|}{ Research Universities } \\
\hline 2004 & 0.873 & 0.105 & 0.919 & 0.476 & 0.984 \\
\hline 2005 & 0.874 & 0.100 & 0.916 & 0.526 & 0.984 \\
\hline 2006 & 0.870 & 0.102 & 0.916 & 0.535 & 0.987 \\
\hline 2007 & 0.868 & 0.099 & 0.908 & 0.528 & 0.980 \\
\hline 2008 & 0.859 & 0.110 & 0.900 & 0.360 & 0.972 \\
\hline 2009 & 0.859 & 0.111 & 0.892 & 0.314 & 0.974 \\
\hline 2010 & 0.869 & 0.111 & 0.910 & 0.334 & 0.975 \\
\hline 2011 & 0.874 & 0.104 & 0.901 & 0.295 & 0.977 \\
\hline 2012 & 0.868 & 0.110 & 0.910 & 0.292 & 0.975 \\
\hline 2013 & 0.864 & 0.104 & 0.901 & 0.364 & 0.978 \\
\hline $10 \mathrm{yr}$ & 0.868 & 0.105 & 0.906 & 0.292 & 0.987 \\
\hline \multicolumn{6}{|c|}{ Comprehensive Universities } \\
\hline 2004 & 0.842 & 0.125 & 0.889 & 0.329 & 0.980 \\
\hline 2005 & 0.840 & 0.114 & 0.875 & 0.445 & 0.976 \\
\hline 2006 & 0.829 & 0.116 & 0.866 & 0.465 & 0.969 \\
\hline 2007 & 0.823 & 0.114 & 0.861 & 0.415 & 0.962 \\
\hline 2008 & 0.815 & 0.123 & 0.858 & 0.318 & 0.970 \\
\hline 2009 & 0.821 & 0.120 & 0.862 & 0.366 & 0.958 \\
\hline 2010 & 0.855 & 0.111 & 0.898 & 0.365 & 0.969 \\
\hline 2011 & 0.856 & 0.108 & 0.899 & 0.434 & 0.969 \\
\hline 2012 & 0.846 & 0.116 & 0.891 & 0.339 & 0.962 \\
\hline 2013 & 0.838 & 0.118 & 0.880 & 0.369 & 0.965 \\
\hline $10 \mathrm{yr}$ & 0.837 & 0.117 & 0.878 & 0.318 & 0.980 \\
\hline
\end{tabular}

University managerial inefficiencies/efficiencies in allocating internal resources to faculty teaching contracts and employment are generated from the SFA estimates. Table 5 presents the institutional inefficiency/efficiency results for the pooled, research, and comprehensive universities. As Table 5 indicates, across all universities, pooled or otherwise, the mean production technical efficiency is below $90 \%$ but is encouraging in that universities are producing relatively well in terms of their graduation rate efficiencies given the resources that are at their disposal and/or managerially allocated within the institution. Of course, as the OLS and SFA results revealed, university efficiencies are dependent upon incoming student 
preparedness, as well as, governmental grants to support student higher education enrollments and managerial decisions related to the employment of teaching faculty. The pooled efficiency results presented in Table 5 indicate a decline in mean university efficiencies beginning in the 2005 academic year and continuing with each consecutive academic year through 2008. Efficiency gains follow with the 2009, 2010, and 2011 academic years. To some extent those gains could be attributed to managerial responses to the Great Recession (December 2007 to June 2009) and slow economic recovery that, for example, when measured in employment gains did not begin until 2011. However, as indicated, university efficiencies once again took a downward turn in both the 2012 and 2013 academic years. In each academic year, the median efficiencies exceed the means and is indicative of the negative skewness among university efficiency outcomes. Likewise, the maximum efficiencies indicate that some universities across the ten academic years are close to full efficiency while the minimum efficiencies suggest that other universities struggle to maintain a reasonably acceptable level of efficiency in producing student graduation success.

Separate results for research and comprehensive universities produce a similar pattern of mean efficiency losses and gains over the ten academic years but with research university gains appearing in only 2010 and 2011 and comprehensive gains stretching over the three academic years, 2009, 2010, and 2011. However, both research and comprehensive universities realize efficiency losses in 2012 and 2013. In each academic year, research university mean efficiencies, as well as median efficiencies, outweigh what comprehensive universities are managerially able to achieve. That advantage of research over comprehensive universities also holds for the maximum achieved efficiencies. For the worst performing, minimum efficiency, universities, research universities begin a downhill slide beginning in 2008. With minimum efficiencies above $50 \%$ in the three previous academic years, 2008 witnesses a decline to a $36 \%$ efficiency and remains at near $30 \%$ to the mid 30\% range. In contrast, comprehensive universities begin to show some improvements beginning in the 2009 academic year, i.e., the minimum efficiency begins a slow climb to the better. The SFA results provided in Table 4 clearly indicate that lower efficiency universities captured in Table 5 are due to lower tenure and tenure track employment decisions relative to higher employment of non-tenure track teaching faculty decisions within universities. By the same token, higher efficiency universities in producing student success are those universities employing relatively more tenure and tenure track faculty relative to non-tenure track faculty. Figures 1,2, and 3 present a clear summary picture of the relationships between managerial decisions of faculty employment and the institutional efficiency in producing student graduation success for all universities pooled, research universities, and comprehensive universities, respectively.

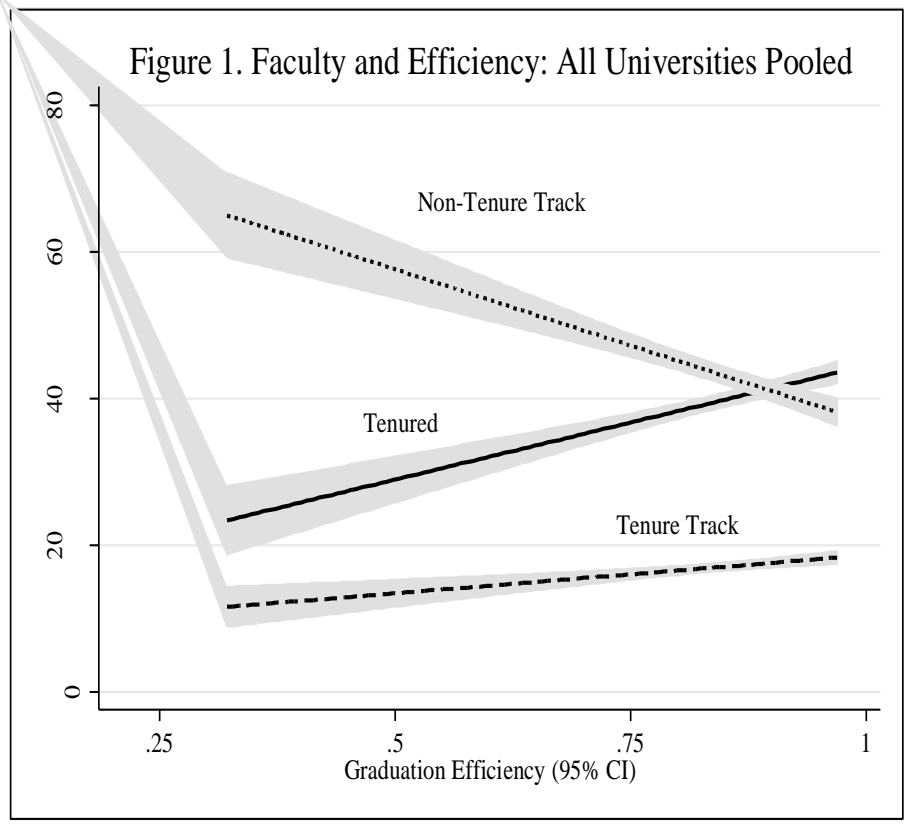



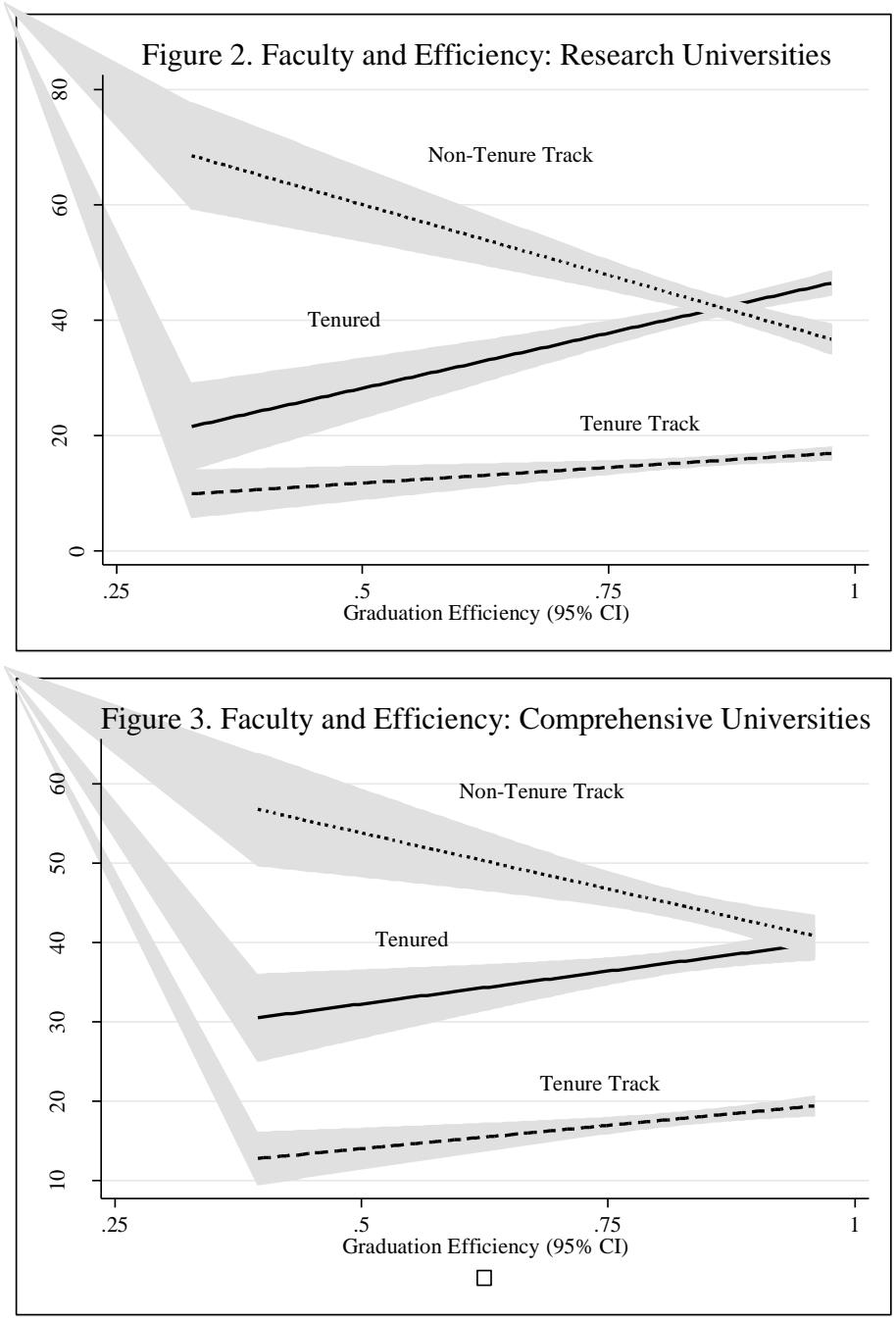

In all cases, increases in the composition of faculty that are tenured have a strong effect on increasing the efficiency of producing student graduation success while increases in the composition of non-tenure track faculty have a detrimental effect on producing student success. Both effects are somewhat stronger among research universities relative to comprehensive universities. The employment composition of tenure track faculty are relatively weak among both research and comprehensive universities and that, of course, is in keeping with the SFA efficiency results of Tables 3 and 4 whereby the tenure track inefficiency coefficients struggled to reach a reasonable level of statistical significance. And while it was suggested that the weaker tenure track effect may be due to the greater research demands placed on faculty at that level, better data on the teaching responsibilities of those faculty would be necessary to drawn stronger conclusions.

\section{Conclusion and Recommendations}

The empirical results of this paper support the notion that the faculty tenure process present in U.S. higher education leads to improvements in the graduation rates of students and increases the efficiency of universities in producing student success. In contrast, there is equally strong empirical evidence presented indicating that increases in the proportion of non-tenure track faculty employment have a negative effect on student graduation success and increases the inefficiency of universities. The results are based on employing panel data over ten academic years, 2004-05 through 2013-14, using both ordinary least squares (OLS) and stochastic frontier analysis (SFA) to test the employment composition effects of tenured faculty, tenure track faculty, and non-tenure track faculty on the graduation success of students. The full panel data consisted of 3,465 observations on public sector research and comprehensive universities offering both undergraduate 
and graduate education. Both the OLS and SFA specifications used control variables as measures of internal budgetary allocations to student support and faculty research support, as well as, student tuition charges, student application acceptance rates, student acceptance enrollment rates, and student enrollment mathematical and verbal aptitude scores. Compared to the OLS specification, the SFA model was used to include the three faculty employment contractual arrangements as inefficiency measures and to subsequently provide overall university efficiency results.

In comparison to previous studies, the current results support the Ehrenberg and Zhang (2005) study that finds part-time and non-tenure track faculty employment reduces graduation rates. However, unlike the current results, that study does not incorporate the effects of tenured faculty and tenure track faculty on effects of graduation rate success. Relative to other previous studies, the current study results are based on reported data for all U.S. Carnegie classified research and comprehensive universities offering both undergraduate and graduate education. Absent the study by Sav (2012a), none of the previous studies have included such an all-inclusive evaluation of U.S. universities. Moreover, relative to that Sav (2012a) study that was constrained to evaluating faculty employment effects over the 2004-09 academic years, the present results are extended to encompass ten academic years 2004-05 through 2013-14 and, therefore, include the potential effects of managerial responses to and effects of the Great Recession on university efficiencies. Yet, the limitations of the present study rest with the available data and the inability to include alternative effects of adjunct faculty and graduate assistant teaching as substitutes to tenure and tenure track faculty by university managers. If that better data becomes available and can be incorporated in the current empirical approach, then better comparisons of faculty or teaching employment effects could be improved for comparison across all previous literature. That would be a fruitful undertaking for future research.

In conclusion, the managerial policy implications emanating from the current results are clear. While university administrators and mangers view the employment of lower salary non-tenure track faculty in substitution for more expensive salary tenure track and tenured faculty as budget saving decision-making, that substitution works against producing improvements in student higher education graduation success and against the institutional efficiency of doing so. Given the changing landscape of funding public higher education in moving toward a greater focus on increased funding tied to increases in university student success outcomes, the path to greater funding support appears to be tied to a reversal in administration decision-making and a clear recommendation for increases in the employment composition of tenure track and tenured teaching faculty. Overall, that suggests that publicly funded U.S. universities are on a potential course of mismanagement and not in sync with external conditions driving their public funding support.

\section{References}

American Association of State Colleges and Universities. (2006). Faculty trends and issues. Policy Matters, $3(4), 1-4$.

Battese, G. E. \& Coelli, T. J. (1995). A model for technical inefficiency effects in a stochastic frontier production function for panel data. Empirical Economics, 20(1), 325-332.

Bettinger, E. P. \& Long, B. T. (2004). Do college instructors matter? The effects of adjuncts and graduate assistants on students' interests and success. National Bureau of Economic Research, Working Paper No. 10370.

Bettinger, E. P. \& Long, B. T. (2010). Does cheaper mean better? The impact of using adjunct instructors on student outcomes. Review of Economics and Statistics, 92(3), 598-613.

Borjas, G. J. (2000). Foreign-born teaching assistants and the academic performance of undergraduates. American Economic Review, 90(2), 355-359.

Cater, B., Lew, B. \& Pivato, M. (2016). The Efficiency of Tenure Contracts in Academic Employment. Journal of Public Economic Theory, DOI: 10.1111/jpet.12201, 1-31.

Coelli, T., Perelman, S. \& Romano, E. (1999).Accounting for environmental influences in stochastic frontier models: With application to international airlines. The Journal of Productivity Analysis, 11(1), 251273.

Ehrenberg, R. G. \& Zhang, L. (2005). Do tenured and tenure-track faculty matter? Journal of Human Resources, 40(3), 647-659.

Fleisher, B., Hashimoto, M. \& Weinberg, B. (2002). Foreign GTAs can be effective teachers of economics. 
Journal of Economic Education, 33(4), 299-325.

GAO, United States Government Accountability Office. (2014). Higher Education State Funding and Policies on Affordability, GAO-15-151, 1-41.

Kezar, A. \& Gehrke, S. (2016). Faculty Composition in Four-Year Institutions: The Role of Pressures, Values, and Organizational Processes in Academic Decision-Making. The Journal of Higher Education, 87(3), 390-419.

Lawrence, J. H., Celis, S. \& Ott, M., (2014). Is the Tenure Process Fair. The Journal of Higher Education, 85(2), 155-192.

National Conference of State Legislators. (2015). Performance-Based Funding for Higher Education, http://www.ncsl.org/research/education/performance-funding.aspx.

Norris, T. (1991). Nonnative English-speaking teaching assistants and student performance. Research in Higher Education, 32(4), 433-438.

Sav, G. T. (2012a). Does Faculty Tenure Improve Student Graduation Rates? Journal of Business Management and Applied Economics, 1(5), 1-19.

Sav, G. T. (2012b). Efficiency Estimates and Rankings Employing Data Envelopment and Stochastic Frontier Analyses: Evaluating the Management of U.S. Public Colleges. Information Management and Business Review, 4(8), 444-452.

Zhang, L., Ehrenberg, R. G. \& Liu, X. (2015). Changing Faculty Employment at Four-Year Colleges and Universities in the United States. NBER Working Paper No. 21827, 1-59. 